\author{
Britta S. von Ungern-Sternberg \\ Jürg Hammer \\ Franz J. Frei \\ Eva-Maria Jordi Ritz \\ Andreas Schibler \\ Thomas O. Erb
}

\section{Prone equals prone? Impact of positioning techniques on respiratory function in anesthetized and paralyzed healthy children}

Received: 16 September 2006

Accepted: 19 April 2007

Published online: 9 June 2007

(C) Springer-Verlag 2007

Parts of the study were presented at the annual meeting of the Association of

Paediatric Anaesthetists in Cardiff 2006 and published as an abstract

(von Ungern-Sternberg BS, Frei FJ,

Hammer J, Erb TO. Prone equals prone? Impact of different techniques of body positioning on functional residual capacity and ventilation distribution in anaesthetised, paralysed pre-school children. Association of Paediatric Anaesthetists of Great Britain \& Ireland, Cardiff 2006, Free Paper No 5, Paed Anaesth 2006; 16:1299).

Funding was received from the Department of Anesthesia, University of Basel Hospital, Switzerland.

B. von Ungern-Sternberg ( $(\bullet) \cdot$ F. Frei •

E. Jordi Ritz - T. Erb

University Children's Hospital, Division of

Anesthesia,

Roemergasse 8, 4005 Basel, Switzerland

e-mail: bvonungern@uhbs.ch

Tel.: +41-22-3723311

Fax: +41-61-6855013

J. Hammer

University Children's Hospital, Division of Pneumology and Intensive Care,

Basel, Switzerland
A. Schibler

Mater Misericordiae Hospital, Division of Pediatric Intensive Care,

Brisbane, Australia

\begin{abstract}
Objectives: Although the prone position is effectively used to improve oxygenation, its impact on functional residual capacity is controversial. Different techniques of body positioning might be an important confounding factor. The aim of this study was to determine the impact of two different prone positioning techniques on functional residual capacity and ventilation distribution in anesthetized, preschool-aged children. Design: Functional residual capacity and lung clearance index, a measure of ventilation homogeneity, were calculated using a sulfur-hexafluoride multibreath washout technique. After intubation, measurements were taken in the supine position and, in random order, in the flat prone position and the augmented prone position (gel pads supporting the pelvis and the upper thorax). Setting: Pediatric anesthesia unit of university hospital. Patients
\end{abstract}

and participants: Thirty preschool children without cardiopulmonary disease undergoing elective surgery. Measurements and results: Mean (range) age was 48.5 (24-80) months, weight $17.2(10.5-26.9) \mathrm{kg}$, functional residual capacity (mean $\pm \mathrm{SD}$ ) $22.9 \pm 6.2 \mathrm{ml}^{.} \mathrm{kg}^{-1}$ in the supine position and $23.3 \pm 5.6 \mathrm{ml}_{\mathrm{kg}} \mathrm{kg}^{-1}$ in the flat prone position, while lung clearance indices were $8.1 \pm 2.3$ vs. $7.9 \pm 2.3$, respectively. In contrast, functional residual capacity increased to 27.6 $\pm 6.5 \mathrm{ml} . \mathrm{kg}^{-1}(p<0.001)$ in the augmented prone position while at the same time the lung clearance index decreased to $6.7 \pm 0.9(p<0.001)$. Conclusions: Functional residual capacity and ventilation distribution were similar in the supine and flat prone positions, while these parameters improved significantly in the augmented prone position, suggesting that the technique of prone positioning has major implications for pulmonary function.

Keywords Anesthesia, general . Respiratory function, pediatric . Functional residual capacity . Ventilation distribution

\section{Introduction}

The prone position has been advocated as a therapeutic measure in order to improve oxygenation [1]. Since its first description by Bryan [1], numerous studies have re- ported conflicting findings regarding the effect of the prone position on pulmonary function. While prone positioning improves arterial oxygen saturation [2-6], the results regarding its effect on functional residual capacity (FRC) are controversial [6-9]. Therefore, additional confounding 
factors such as changes in ventilation distribution or differences in positioning techniques might be important. Positioning techniques such as flat versus augmented prone positions might exert different degrees of pressure on the abdominal contents with differences in the cephalic displacement of the diaphragm $[8,9]$.

Optimizing FRC is of particular importance in children undergoing anesthesia or sedation because children, relative to adults, have smaller elastic retraction forces and a lower relaxation volume that makes them more prone to airway collapse [10, 11]. Moreover, children are particularly vulnerable to hypoxemia because of their higher oxygen demand per kilogram body weight [12].

The purpose of the present study was to evaluate the impact of two prone positioning techniques on FRC and ventilation homogeneity in anesthetized children with healthy lungs [13]. We hypothesized that compared with the flat prone position, augmented prone positioning would improve FRC and ventilation distribution.

\section{Methods}

Following approval by the local ethics committee in Basel, Switzerland, and after obtaining parental written informed consent, 30 otherwise healthy children, ASA I, 2-6 years of age, scheduled for elective surgery (not involving the thorax or abdomen) under general anesthesia with endotracheal intubation were included in this study. Children with known cardiopulmonary diseases or thoracic deformities were excluded from participation in the study.

One hour before the operation, patches of an eutectic mixture of local anesthetics (EMLA) were applied to the dorsal side of each child's hands. All patients were premedicated with $0.3 \mathrm{mg} \cdot \mathrm{kg}^{-1}$ midazolam administered orally or rectally $15 \mathrm{~min}$ before induction of general anesthesia. In uncooperative patients, nitrous oxide $70 \%$ in oxygen was administered for the insertion of an intravenous cannula. Nitrous oxide was immediately stopped when venous access was achieved. General anesthesia was induced with propofol $3-4 \mathrm{mg} . \mathrm{kg}^{-1}$ i.v. and fentanyl $3 \mu \mathrm{g} . \mathrm{kg}^{-1}$ i.v. Tracheal intubation was facilitated with rocuronium $0.6 \mathrm{mg} \cdot \mathrm{kg}^{-1}$ i.v. and all patients were intubated with a cuffed endotracheal tube (Microcuff, Heidelberg, Germany). Anesthesia was maintained with a propofol infusion $\left(12 \mathrm{mg} \cdot \mathrm{kg}^{-1} \mathrm{~h}^{-1}\right.$ for the first $10 \mathrm{~min}$ of general anesthesia, $9 \mathrm{mg} \cdot \mathrm{kg}^{-1} \mathrm{~h}^{-1}$ for the next $10 \mathrm{~min}$, and then $6 \mathrm{mg} \cdot \mathrm{kg}^{-1} \mathrm{~h}^{-1}$ ) [14]. Muscle relaxation was monitored with a nerve stimulator while total neuromuscular blockade was defined as no tactile twitch on a train-of-four stimulation. Throughout the study period, the muscle relaxation was tested by train-of-four stimulation every $12 \mathrm{~s}$. In the case of reappearance of twitching, additional doses of rocuronium were given.
The first set of measurements was performed $5 \mathrm{~min}$ after intubation in the supine position. The patients were then turned into the prone position; they were positioned either flat prone on the operating table or "augmented" with gel pads (Pur Gel ${ }^{\mathrm{TM}}$, Universal Sandsäcke Art. No. PG0410SSB0 and/or PG0514LSB0, B+P Beatmungsprodukte $\mathrm{GmbH}$, Neunkirchen-Seelscheid, Germany) [15, 16]. The gel pads were positioned under the upper third of the thorax and under the pelvis. The size and/or number of the gel pads was chosen to ensure free movement of the abdomen during the entire respiratory cycle. In this position, the abdomen does not touch the operating table during maximal inspiration. The order of these two positioning techniques was randomized using blocked randomization that was obtained using computer-generated random numbers. The identity of the random numbers was concealed from the investigators until used by means of sealed envelopes which had been filled with the random numbers by a person independent of the study team. During the measurements, the arms were kept stable positioned in parallel to the thorax [17] and the head was turned to the side. Measurements were performed 5 min after completion of positioning. The operating room table was not elevated but was kept completely horizontal during the entire experiment.

During anesthesia, a Centiva/ 5 critical care ventilator (Datex Ohmeda, Helsinki, Finland) was used. Settings were as follows: $\mathrm{F}_{\mathrm{i}} \mathrm{O}_{2}=0.5$ and tidal volume of $8 \mathrm{ml} . \mathrm{kg}^{-1}$ body weight during the whole study period. Respiratory rate was adapted in order to achieve an end-tidal carbon dioxide of 4-5 $\mathrm{kPa}$. The ventilator delivered a continuous bypass flow that was needed to ensure an exact delivery of the tracer gas at all times. This bypass flow in the breathing system $(20 \mathrm{l} / \mathrm{min})$ created a PEEP of $3 \mathrm{cmH}_{2} \mathrm{O}$ in the system throughout the study period.

For the FRC measurements, an ultrasonic transit-time airflow meter (Exhalyzer D with ICU insert, Eco Medics, Duernten, Switzerland) that simultaneously measures flow and molar mass of the breathing gas was placed between the endotracheal tube and the breathing circuit. The technical setup of the measurement equipment has been described previously [18]. Briefly, this airflow meter combines accurate flow measurements with instantaneous mainstream measurements of molecular mass in a single sensor. This analysis is based on an ultrasonic transit time detection measured at a high sampling frequency $(400 \mathrm{~Hz})$ with piezoelectric sensors that demonstrate a high linearity over a wide pressure-amplitude range.

The application of sulfur hexafluoride $\left(\mathrm{SF}_{6}\right.$, molecular mass $146 \mathrm{~g} \mathrm{~mol}^{-1}$ ) as a tracer gas into the inspiratory part of the breathing system increases the total molecular mass of the breathing gas until a steady state is reached. Following the discontinuation of $\mathrm{SF}_{6}$, the molecular mass decreases breath by breath until a steady state is reached 
as soon as the $\mathrm{SF}_{6}$ has been completely washed out of the lungs (multibreath washout technique). Analysis of the washout curve allows for calculation of the FRC, physiological dead space volume, lung clearance index (LCI) and mean dilution number (MDN). LCI and MDN are commonly used to measure the degree of ventilation distribution and are sensitive indicators of peripheral airway collapse [19-23]. The LCI is calculated as the cumulative expired volume needed to lower the end-tidal tracer gas $\left(\mathrm{SF}_{6}\right)$ concentration to $1 / 40$ of the starting concentration divided by the FRC, i.e., the number of lung volume turnovers needed to clear the lungs of the marker gas [22, 23]. MDN is the ratio between the first and the zero-th moments of the washout curve. The number of volume turnovers was calculated using the cumulative expired alveolar volume [20, 21]. Calculations of FRC, dead space volume, MDN, and LCI were performed using Spiroware software (Version 1.5.2, ndd Medizintechnik AG, Zurich, Switzerland). Dead space was calculated using Fowler's method.

\section{Statistics}

Sample size calculations were performed using nQuery Advisor 4.0 software (Statistical Solutions Ltd, Boston, MA, USA). Based on separate pilot data, a sample size of 30 patients was calculated to have a power of $90 \%$ at a 0.05 significance level using a single-group repeated-measures analysis of variance (ANOVA) to detect a difference in means across the three levels of the repeated measures factor characterized by an effect size of 0.15 .

The distribution of data was tested using a Shapiro-Wilk test; accordingly, data with normal distribution were expressed as mean $\pm \mathrm{SD}$ and data not having a normal distribution were expressed as median (interquartile range). A repeated-measures ANOVA was used to compare FRC, MDN, and LCI between the different study conditions. Post hoc, a Bonferroni test was used to adjust for multiple comparisons. A value of $p<0.05$ was considered statistically significant. Results were analyzed using the StatView for Windows (SAS Institute Inc., Cary, NC, USA, Version 5.0.1).

\section{Results}

All 30 children were successfully studied. Patient characteristics are shown in Table 1. Additional doses of rocuronium were administered in 16 children. There were no significant differences in any parameters between the supine and the flat prone position. In contrast, in the augmented prone position, FRC was higher and LCI, MDN, and tidal volume to FRC ratio significantly lower than with the supine and the flat prone position (Table 2, Fig. 1). The mean coefficient of variation of the FRC measurements was 2.6 (2.0). Dead space volume did not change throughout the study period. The mean

Table 1 Characteristics of patients $(n=30)$

\begin{tabular}{lc}
\hline Males:females & $19(63 \%): 11(37 \%)$ \\
Age (months) & $48.5(24-80)$ \\
Height $(\mathrm{cm})$ & $101.8(81-128)$ \\
Weight $(\mathrm{kg})$ & $17.2(10.5-26.9)$ \\
Smoke exposure $(n)$ & $5(17 \%)$ \\
Family history of asthma $(n)$ & $5(17 \%)$ \\
Family history of severe allergic reactions $(n)$ & $3(10 \%)$ \\
\hline
\end{tabular}

Values are median (range) or number (proportion)

Table 2 Measured parameters at the different assessments

\begin{tabular}{|c|c|c|c|c|c|c|}
\hline \multirow[t]{2}{*}{ Parameter } & \multicolumn{3}{|c|}{ Position } & \multicolumn{3}{|c|}{$p$ value $^{\mathrm{a}}$} \\
\hline & Supine (S) & Prone, augmented (PA) & Prone, flat (PF) & S vs. PA & S vs. PF & PA vs. PF \\
\hline FRC (ml) & $400 \pm 159$ & $480 \pm 169$ & $405 \pm 145$ & $<0.0001$ & 0.6327 & $<0.0001$ \\
\hline $\mathrm{FRC}\left(\mathrm{ml} . \mathrm{kg}^{-1}\right)$ & $22.9 \pm 6.2$ & $27.6 \pm 6.5$ & $23.3 \pm 5.6$ & $<0.0001$ & 0.3867 & $<0.0001$ \\
\hline LCI & $8.1 \pm 2.3$ & $6.7 \pm 0.9$ & $7.9 \pm 2.3$ & $<0.0001$ & 0.4332 & 0.0002 \\
\hline MDN & $2.11 \pm 0.6$ & $1.76 \pm 0.3$ & $2.09 \pm 0.8$ & 0.0003 & 0.7689 & 0.0007 \\
\hline $\mathrm{V}_{\mathrm{D}}\left(\mathrm{ml} \cdot \mathrm{kg}^{-1}\right)$ & $1.21 \pm 0.2$ & $1.22 \pm 0.3$ & $1.22 \pm 0.2$ & 0.6195 & 0.8577 & 0.7507 \\
\hline $\mathrm{V}_{\mathrm{T}}\left(\mathrm{ml} \cdot \mathrm{kg}^{-1}\right)$ & 8 & 8 & 8 & & & \\
\hline $\mathrm{V}_{\mathrm{T}} / \mathrm{FRC}$ & $0.36 \pm 0.1$ & $0.29 \pm 0.1$ & $0.35 \pm 0.1$ & $<0.0001$ & 0.1441 & $<0.0001$ \\
\hline
\end{tabular}

${ }^{a}$ As determined by a repeated-measures analysis of variance.

$F R C$, functional residual capacity; $L C I$, lung clearance index; $M D N$, mean dilution number; $V_{D}$, dead space volume; $V_{T}$, tidal volume 


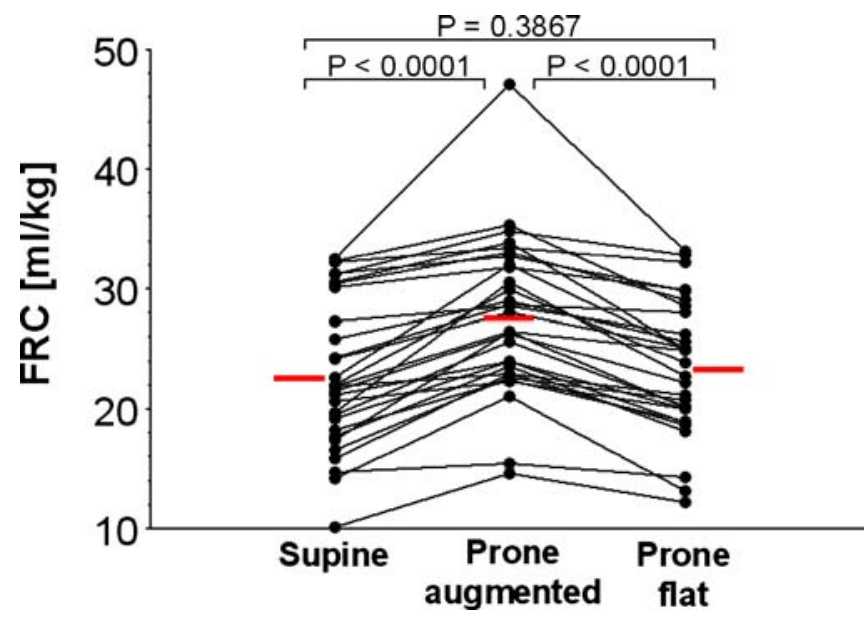

Fig. 1 Functional residual capacity $(F R C)$ at the three assessments

coefficient of variation for the dead space measurements was $3.04(2.5)$.

\section{Discussion}

This study examined the effects of positioning techniques on FRC and ventilation distribution in anesthetized, paralyzed preschool-aged children with healthy lungs. In contrast to supine or flat prone positioning, augmented prone positioning significantly improved FRC and ventilation distribution.

The impact of the prone position on FRC is controversial $[8,9,24]$. In line with the present data, a study performed in a small number of children with and without lung disease failed to reveal differences in FRC between the supine and the flat prone positions [8]. Also in agreement with our findings, Pelosi et al. [9] showed an increase in FRC of about 30\% in anesthetized adults in the augmented prone position compared with the supine position.

Ventilation homogeneity can be described by several indices and calculated by analyzing the washout curve of an insoluble tracer gas (such as $\mathrm{SF}_{6}$ ) [25]. The LCI and MDN are sensitive parameters in detecting peripheral airway collapse [23, 25]. Our data corroborate results obtained from mechanically ventilated healthy animals showing a more even ventilation distribution in the prone than in with the supine position $[26,27]$. This indicates that in the prone position ventilation is redirected into different lung areas in paralyzed, mechanically ventilated subjects. Furthermore, the effect of gravity on ventilation distribution caused by different body positions has been assessed with krypton gas isotopes: in the prone position ventilation distribution is more uniform [28], in contrast to the supine position, where the backward-falling heart can cause a restricted ventilation of the dependent lungs [29].
The changes in FRC and ventilation distribution in the present study probably result from anatomical changes based on positioning: in the supine position, abdominal contents exert a cephalic pressure against the diaphragm with a dorso-ventral gradient. Under complete neuromuscular blockade, diaphragmatic muscular tone is absent. Therefore, the weight of the abdominal contents is no longer opposed by the diaphragm. This results in cephalic displacement of the posterior regions of the diaphragm [30]. In addition, the dorsal area of the diaphragm has a smaller radius of curvature than the ventral area. Thus, according to the law of Laplace, greater pressure will be exerted dorsally for any given wall tension. These changes might be more pronounced in children than in adults because of the former's more compliant chest walls that result in an increased tendency towards collapse of the small peripheral airways [31-33].

The impact of neuromuscular blockade on FRC and ventilation distribution in the current study cannot be quantified. However, when comparing our present results with a previous study conducted by our group that focused on the impact of neuromuscular blockade in preschool children and that used a similar study design, FRC values in the supine position were similar under neuromuscular blockade $\left[23.0(5.3) \mathrm{ml} . \mathrm{kg}^{-1}\right.$ and 22.9 (6.2) $\mathrm{ml} . \mathrm{kg}^{-1}$, respectively] but significantly lower than after initial induction of anesthesia without neuromuscular blockade (25.6 ml. $\left.\mathrm{kg}^{-1}\right)$ [34]. The absence of muscular tone might lead to an increase in the changes caused by body positioning; diaphragmatic tone is absent, leading to an unopposed cephalic shift of the abdominal contents as described above.

During mechanical ventilation in the supine position, the ventral parts of the rib cage have a high chest wall compliance [35]. In contrast, in the prone position, rib cage movements are restricted and chest wall compliance is decreased [35]. Impaired chest wall compliance increases pleural pressures and thus increases transpulmonary pressure gradients. This might allow previously collapsed segments to be re-expanded [8]. Furthermore, a more even ventilation distribution might result from a reduced vertical pleural pressure gradient [36]. The pressure of the abdominal contents is lower in the prone position than in the supine position, resulting in a caudal displacement of the diaphragm. The absence of significant differences in FRC between the flat prone and the supine position in the present study can be best explained by the restricted movement of the abdomen and the lower chest wall compliance in the flat prone position and by children being paralyzed and mechanically ventilated with a PEEP of $3 \mathrm{cmH}_{2} \mathrm{O}$, conditions that might lessen the degree of caudal displacement of the diaphragm in the flat prone position. However, anatomic changes are more pronounced in the augmented prone position because this allows the abdomen to move more freely [9]. 
In our study, the tidal volume to FRC ratio was higher in the flat prone and supine positions than in the augmented prone position, as the tidal volume was kept constant throughout the study period while FRC changed with the different positioning techniques. Theoretically this could have affected the degree of ventilation inhomogeneity, because calculations of LCI and MDN are not completely independent of the tidal volume to FRC ratio [37]. However, these effects are not sensitive enough to reflect the ventilation maldistribution that occurs with a change of posture or a change of tidal volume to FRC ratio [38]. Nevertheless, the decreased tidal volume to FRC ratio in the augmented prone position is normally associated with a decrease in ventilation homogeneity [25], leading to the improved ventilation distribution observed in the augmented prone position. The lack of change in the dead space to tidal volume ratio between the different positioning techniques additionally underlines the significant improvement in the augmented prone position compared with the flat prone and supine positions. This suggests that factors other than changes in tidal volume to FRC ratio, such as partially collapsed alveoli and less well distended distal bronchi, contributed to the observed ventilation maldistribution in the supine or flat prone positions.

Among the many factors that make children vulnerable to hypoxemia when undergoing sedation or anesthesia are alterations in lung mechanics. Most anesthetic agents promote atelectasis formation shortly after induction, leading to a decrease in FRC and ventilation homogeneity and potentially to hypoxemia [39-42]. Therefore, prevention of atelectasis during anesthesia or sedation is important in all children as atelectasis persists well into the postinterventional period and can have a negative impact on patient recovery [42].

All measurements were made with a PEEP of $3 \mathrm{cmH}_{2} \mathrm{O}$ caused by the continuous bypass flow necessary to enable a constant delivery of the tracer gas. This might be considered a limitation of the study. The impact of this effect cannot be quantified at present; however, direct comparisons of the different positions should not have been affected since all measurements were taken under equivalent conditions. Furthermore, a PEEP of $3 \mathrm{cmH}_{2} \mathrm{O}$ is often used in clinical practice and therefore does not diminish the relevance of our data. However, since only children with healthy lungs were studied, the clinical implications in children with acute or chronic lung injury are unknown.
All patients were measured first in the supine position and then turned, in a randomized order, into the augmented prone and flat prone positions. Therefore, the time course could have potentially affected the changes in FRC and LCI between the supine and the prone positions. However, FRC and LCI have been shown to remain constant in preschool children under propofol anesthesia $\left(\mathrm{F}_{\mathrm{i}} \mathrm{O}_{2}=0.5\right)$ during a study period of similar duration [43]. Additionally, FRC decreases immediately after induction of anesthesia in adults but then remains stable for at least $1 \mathrm{~h}$ [41]. Therefore, in the present study a time effect was unlikely to have been a confounding factor for the observed changes in FRC, LCI, and MDN.

A high interindividual variability in the FRC values was observed in this study. However, a wide range of interindividual FRC values was a regular finding in all studies of our group in anesthetized preschool children when using the SF6 multibreath washout technique, independent of the method of breathing (spontaneous versus mechanical ventilation), the anesthetic agent used (propofol versus ketamine), body positioning (supine, prone, lateral), the use of regional techniques or even before and after cardiac bypass [34, 43-47]. Although absolute values vary among the patients, the relative changes between the different assessments show a lower variability. These interindividual differences are most probably based on the different susceptibility to changes in respiratory mechanics after induction of anesthesia, which varies greatly between patients. In addition, some methodological issues (e.g. gas temperature, pressurization) using an ultrasonic flowmeter for FRC measurements cannot be completely excluded. Of note, however, Sivan et al. [48] also found a large interindividual variability in FRC values in intubated children when using a nitrogen washout technique.

In the present study, the calculated dead space was approximately $1.2 \mathrm{ml} / \mathrm{kg}$ in all positions, which is in line with previous results in intubated children [34, 45, 49] and differs substantially from that observed in spontaneously breathing anesthetized preschool children $(2.8 \mathrm{ml} / \mathrm{kg})$ [44, 50]; this can be explained by the decrease in dead space following intubation.

In conclusion, the augmented prone position, in contrast to the flat prone position, increased FRC and could be beneficial when optimizing FRC and ventilation distribution in paralyzed, mechanically ventilated healthy children. This suggests that the technique used for prone positioning might affect pulmonary function. 


\section{References}

1. Bryan AC (1974) Comments of a devil's advocate. Am Rev Respir Dis 110 [Suppl]:143-144

2. Murdoch IA, Storman MO (1994) Improved arterial oxygenation in children with the adult respiratory distress syndrome: the prone position. Acta Paediatr 83:1043-1046

3. Gattinoni L, Pelosi P, Vitale G, Pesenti A, D'Andrea L, Mascheroni D (1991) Body position changes redistribute lung computed-tomographic density in patients with acute respiratory failure. Anesthesiology 74:15-23

4. Douglas WW, Rehder K, Beynen FM, Sessler AD, Marsh HM (1977) Improved oxygenation in patients with acute respiratory failure: the prone position. Am Rev Respir Dis 115:559-566

5. Langer M, Mascheroni D, Marcolin R, Gattinoni L (1988) The prone position in ARDS patients. A clinical study. Chest 94:103-107

6. Wagaman MJ, Shutack JG, Moomjian AS, Schwartz JG, Shaffer TH, Fox WW (1979) Improved oxygenation and lung compliance with prone positioning in neonates. J Pediatr 94:787-791

7. Agostini W, Mead J (1964) Statics of the respiratory system. In: Fenn WO, Rhan H (eds.) Handbook of physiology, vol I: Respiration. American Physiological Society, Washington, DC, pp 387-409

8. Numa AH, Hammer J, Newth CJ (1997) Effect of prone and supine positions on functional residual capacity, oxygenation, and respiratory mechanics in ventilated infants and children. Am J Respir Crit Care Med 156:1185-1189

9. Pelosi P, Croci M, Calappi E, Cerisara M, Mulazzi D, Vicardi P, Gattinoni L (1995) The prone positioning during general anesthesia minimally affects respiratory mechanics while improving functional residual capacity and increasing oxygen tension. Anesth Analg 80:955-960

10. Mansell A, Bryan C, Levison H (1972) Airway closure in children. J Appl Physiol 33:711-714

11. Nunn JF (1987) Elastic forces and lung volumes. In: Nunn JF (ed) Applied respiratory physiology, 3rd edn. Butterworth, London, pp 23-45

12. Lumb AB (2000) Pregnancy, neonates and children. In: Nunn's applied respiratory physiology, 5th edn. Butterworth-Heinemann, Oxford, pp 319-333
13. von Ungern-Sternberg BS, Hammer J, Frei FJ, Erb TO (2006) Prone equals prone? - Impact of different techniques of body positioning on functional residual capacity and ventilation distribution in anaesthetised, paralysed pre-school children (abstract). Paed Anaesth 16:1299

14. Steur RJ, Perez RS, De Lange JJ (2004) Dosage scheme for propofol in children under 3 years of age. Paediatr Anaesth 14:462-467

15. Kornecki A, Frndova H, Coates AL, Shemie SD (2001) A randomized trial of prolonged prone positioning in children with acute respiratory failure. Chest 119:211-218

16. Smith RH (1974) One solution to the problem ot the prone position for surgical procedures. Anesth Analg 53:211-224

17. Lumb AB, Nunn JF (1991) Respiratory function and ribcage contribution to ventilation in body positions commonly used during anaesthesia. Anesth Analg 73:422-426

18. Schibler A, Hammer J, Isler R, Buess C, Newth CJ (2004) Measurement of lung volume in mechanically ventilated monkeys with an ultrasonic flow meter and the nitrogen washout method. Intensive Care Med 30:127-132

19. East TD, Andriano KP, Pace NL (1987) Automated measurement of functional residual capacity by sulfur hexafluoride washout. J Clin Monit 3:14-21

20. Schibler A, Hall GL, Businger F, Reinmann B, Wildhaber JH, Cernelc M, Frey U (2002) Measurement of lung volume and ventilation distribution with an ultrasonic flow meter in healthy infants. Eur Respir J 20:912-918

21. Larsson A, Linnarsson D, Jonmarker C, Jonson B, Larsson H, Werner O (1987) Measurement of lung volume by sulfur hexafluoride washout during spontaneous and controlled ventilation: further development of a method. Anesthesiology 67:543-550

22. Gustafsson PM, Kallman S, Ljungberg H, Lindblad A (2003) Method for assessment of volume of trapped gas in infants during multiple-breath inert gas washout. Pediatr Pulmonol 35:42-49

23. Gustafsson PM, Aurora P, Lindblad A (2003) Evaluation of ventilation maldistribution as an early indicator of lung disease in children with cystic fibrosis. Eur Respir J 22:972-979
24. Curley MA (1999) Prone positioning of patients with acute respiratory distress syndrome: a systematic review. Am J Crit Care 8:397-405

25. Larsson A, Jonmarker C, Werner O (1988) Ventilation inhomogeneity during controlled ventilation. Which index should be used? J Appl Physiol 65:2030-2039

26. Treppo S, Mijailovich SM, Venegas JG (1997) Contributions of pulmonary perfusion and ventilation heterogeneity in V/Q measured by PET. J Appl Physiol 82:1163-1176

27. Mure M, Domino KB, Lindahl SG, Hlastala MP, Altemeier WA, Glenny RW (2000) Regional ventilation-perfusion distribution is more uniform in the prone position. J Appl Physiol 88:1076-1083

28. Amis TC, Jones HA, Hughes JM (1984) Effect of posture on inter-regional distribution of pulmonary ventilation in man. Respir Physiol 56:145-167

29. Lumb AB (2000) Distribution of pulmonary ventilation and perfusion. In: Nunn's applied respiratory physiology, 5th edn. Butterworth-Heinemann, Oxford, pp 163-199

30. Froese AB, Bryan AC (1974) Effects of anesthesia and paralysis on diaphragmatic mechanics in man. Anesthesiology 41:242-255

31. Papastamelos C, Panitch HB, England SE, Allen JL (1995) Developmental changes in chest wall compliance in infancy and early childhood. J Appl Physiol 78:179-184

32. Bancalari E, Clausen J (1998) Pathophysiology of changes in absolute lung volumes. Eur Respir J 12:248-258

33. Stocks J (1999) Respiratory physiology during early life. Monaldi Arch Chest Dis 54:358-364

34. von Ungern-Sternberg BS, Hammer J, Schibler A, Frei FJ, Erb TO (2006) Decrease of functional residual capacity and ventilation homogeneity following neuromuscular blockade in anesthetized young infants and preschool children. Anesthesiology 105:670-675

35. Pelosi P, Tubiolo D, Mascheroni D, Vicardi P, Crotti S, Valenza F, Gattinoni L (1998) Effects of prone position on respiratory mechanics and gas exchange during acute lung injury. Am J Respir Crit Care Med 157:387-393 
36. Mutoh T, Guest RJ, Lamm WJE, Albert RK (1992) Prone position alters the effect of volume overload on regional pleural pressures and improves hypoxemia in pigs in vivo. Am J Respir Crit Care Med 146:300-306

37. Habib RH, Lutchen KR (1991) Moment analysis of a multibreath nitrogen washout based on an alveolar gas dilution number. Am Rev Respir Dis 144:513-519

38. Gronkvist M, Bergsten E, Gustafsson PM (2002) Effects of body posture and tidal volume on inter- and intraregional ventilation distribution in healthy men. J Appl Physiol 92:634-642

39. Rigg JR (1981) Pulmonary atelectasis after anaesthesia: pathophysiology and management. Can Anaesth Soc J 28:305-313

40. Damgaard-Pedersen K, Qvist T (1980) Pediatric pulmonary CT-scanning. Anaesthesia-induced changes. Pediatr Radiol 9:145-148

41. Don HF, Wahba WM, Craig DB (1972) Airway closure, gas trapping, and the functional residual capacity during anesthesia. Anesthesiology 36:533-539
42. Duggan M, Kavanagh BP (2005) Pulmonary atelectasis: a pathogenetic perioperative entity. Anesthesiology 102:838-854

43. von Ungern-Sternberg BS, Regli A, Frei FJ, Hammer J, Schibler A, Erb TO (2006) The effect of caudal block on functional residual capacity and ventilation homogeneity in healthy children. Anaesthesia 61:758-763

44. von Ungern-Sternberg BS, Frei FJ, Hammer J, Schibler A, Doerig R, Erb TO (2007) Impact of depth of propofol anaesthesia on the functional residual capacity and ventilation distribution in healthy preschool children. $\mathrm{Br}$ J Anaesth 98:503-508

45. von Ungern-Sternberg BS, Regli A, Schibler A, Hammer J, Frei FJ, Erb TO (2007) Impact of positive end-expiratory pressure on functional residual capacity and ventilation homogeneity impairment in anesthetized children exposed to high levels of inspired oxygen. Anesth Analg 104 (6) (in press)
46. Regli A, Habre W, Saudan S, Mamie C, Erb TO, von Ungern-Sternberg BS (2007) Impact of Trendelenburg positioning on functional residual capacity and ventilation homogeneity in anaesthetised children. Anaesthesia 62:451-455

47. von Ungern-Sternberg BS, Saudan S, Regli A, Schaub E, Erb TO, Habre W (2007) Should the use of modified Jackson Rees T-piece breathing system be abandoned in preschool children? Paed Anaesth (in press)

48. Sivan Y, Deakers TW, Newth CJ (1990) Functional residual capacity in ventilated infants and children. Pediatr Res 28:451-454

49. von Ungern-Sternberg BS, Frei FJ, Hammer J, Erb TO (2005) Impact of positioning on functional residual capacity and ventilation homogeneity in anaesthetised preschool children. Swiss Med Weekly 135 [Suppl 148]:13

50. von Ungern-Sternberg BS (2006) Impact of depth of propofol vs ketamine sedation on functional residual capacity and ventilation distribution in preschool aged children. Eur J Anaesth 23 [Suppl 37]:176 